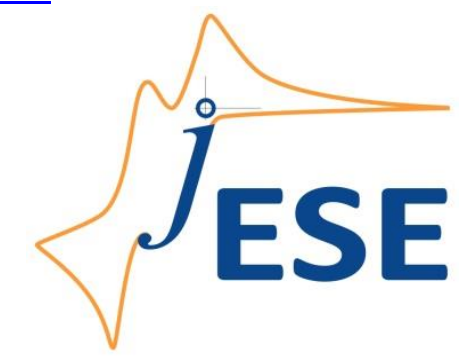

Open Access: ISSN 1847-9286

www.jESE-online.org

Original scientific paper

\title{
Affordable voltammetric sensor based on anodized disposable pencil graphite electrodes for sensitive determination of dopamine and uric acid in presence of high concentration of ascorbic acid
}

\author{
Preethi Sankaranarayanan ${ }^{\bowtie}$ and Sangaranarayanan M. Venkateswaran \\ Department of Chemistry, Indian Institute of Technology Madras, Chennai, Tamil Nadu - 600036, \\ India
}

Corresponding author: ${ }^{\circledR}$ preethi92.us@gmail.com; Tel.: +919500955589

Received: February 3, 2020; Revised: February 28, 2020; Accepted: March 2, 2020

\begin{abstract}
A simple, disposable and low - cost voltammetric sensor based on the anodized pencil graphite electrode (APGE) for the simultaneous determination of dopamine (DA) and uric acid (UA) is demonstrated. The physico-chemical properties of the pencil graphite electrode (PGE) before and after anodization were analyzed using FT-IR, FT-Raman, SEM and EIS characterization techniques. In comparison to PGE, APGE exhibited excellent electrochemical activity towards the simultaneous detection of DA and UA with peak-topeak separation of about $0.18 \mathrm{~V}$ even in the presence of high concentration $(2 \mathrm{mM})$ of ascorbic acid (AA). The discrimination of APGE towards $A A$ was rationalized through the absence of favorable surface interactions between oxygen rich functional groups on the surface of $A P G E$ and $A A$. Using DPV without any pre-concentration step and under optimized conditions, APGE displayed a linear range of 1-80 $\mu \mathrm{M}$ with an estimated limit of detection ( $L O D, 3 \sigma / \mathrm{m}$ ) of $0.008 \mu \mathrm{M}$ and $0.014 \mu \mathrm{M}$ for DA and $U A$, respectively. Moreover, a higher sensitivity in comparison to other previously reported pretreated pencil graphite electrodes was observed for DA (34.32 $\mu \mathrm{A} / \mu \mathrm{M})$ and UA (12.33 $\mu \mathrm{A} / \mu \mathrm{M})$. The practical applicability of APGE was demonstrated through the estimation of DA in human blood serum and UA in urine samples.
\end{abstract}

\section{Keywords}

Anodization; pencil graphite electrode; dopamine; uric acid; ascorbic acid.

\section{Introduction}

Neurotransmitters are an important class of biomolecules that play a vital role in control and effective functioning of the central nervous, cardiovascular, renal and hormonal systems [1,2]. 
Dopamine (DA) is one of the neurotransmitters in the family of catecholamines, which exists as organic cations in brain tissues and body fluids. Abnormal or low level of DA in the human body leads to many psycho-somatic disorders [3.4]. Like DA, uric acid (UA) is another class of biomolecules which forms in the body as one of the principal end-products of the purine metabolism. Several diseases such as Lysch - Nyhan syndrome, hyperuricaemia and gout are the consequences of abnormal levels of UA [5-10]. Therefore, accurate detection of DA and UA in body fluids like blood serum and urine is of great clinical importance for an effective point of care analysis.

In the recent past, due to their fast processing time and cost effectiveness, electroanalytical techniques have been favored over other traditional analytical techniques for the detection of DA and UA [11-13]. However, electrochemical detection of these two compounds at conventional electrodes such as bare carbon electrode has the following difficulties [14-16]:

1. DA and UA coexist with electrochemically active ascorbic acid (AA) in biological fluids, thereby, causing mutual interference during detection.

2. DA and UA have similar oxidation potentials, thereby rendering their electrochemical detection relatively challenging task.

3. The concentration levels of UA and AA in body fluids are significantly higher in comparison with DA.

4. During electrochemical detection of these compounds, their oxidation products adsorb or electropolymerize on the electrode surfaces, thereby reducing their reproducibility and reusability.

In order to overcome the above-mentioned drawbacks of bare carbon electrodes, many researchers have employed novel materials as chemical modifiers [17], including polymeric materials [18,19], ionic liquids [20], carbon nanotubes (CNTs) [20-23], nanoparticles (NPs) [24] and nanocomposites $[25,26]$. From this perspective, the simplest way in which a bare carbon electrode can be chemically modified is electrochemical pretreatment by applying high potential using either chronoamperometry (CA) or cyclic voltammetry (CV) technique. During the anodization process (application of high positive potential) of bare carbon electrode, oxygen rich groups such as $-\mathrm{OH}$, $-\mathrm{COOH}$, etc. [5,27-29], are formed on the electrode surface. Due to the polar nature of these oxygen rich groups, the anodized carbon electrodes exhibit affinity towards adsorption of polar molecules and also enhance the wettability of electrodes $[5,27,30]$. Furthermore, at neutral or physiological $\mathrm{pH}, \mathrm{DA}$ and UA exist as positively charged while AA as negatively charged ions [31,32]. Therefore, these molecules can be selectively determined at anodized carbon electrodes because of the inherent polar nature.

Among various carbon electrodes, pencil graphite electrodes (PGEs) have recently received widespread attention. Due to their $\mathrm{sp}^{2}$ hybridized carbon, PGEs exhibit good conductivity, adsorption properties, low background current, high sensitivity, and ease of preparation and surface modification [24,33-37]. Moreover, in comparison to glassy carbon electrodes (GCEs), PGEs offer easy renewability of the electrode surface, which plays an important role in subsequent analysis [24]. However, only few reports are available wherein pretreated PGEs have been utilized for the detection of DA and UA $[11,38,39]$. For example, Ozcan et al. have developed the electrochemically over-oxidized PGE modified by poly(pyrrole-3-carboxylic acid) for the detection of DA in blood serum samples, where chronoamperometry was employed for carrying out the anodization [38]. Further, Alipour et al. reported a pre-treated PGE for the simultaneous determination of DA and UA in biological samples wherein, cyclic voltammetry was employed to prepare anodized PGEs [11]. Though, these studies have reported good figures of merit, the analyses were preceded by a pre-concentration step and exhibited short linear range of calibration plots. 
Hence, in the present study we have developed anodized disposable pencil graphite electrodes (APGEs) for the selective and sensitive determination of DA and UA in the presence of high concentration of AA without any pre-concentration step. PGEs were anodized using a simple chronoamperometric method and formed APGEs were subsequently analyzed using various material characterization techniques. The discriminating nature of APGE has been rationalized through the formation of oxygen containing groups on the electrode surface.

\section{Experimental}

\section{Chemicals and reagents}

$\mathrm{K}_{2} \mathrm{HPO}_{4}$ (Fisher Scientific, $99.5 \%$ ), $\mathrm{KH}_{2} \mathrm{PO}_{4}$ (SRL, $99.5 \%$ ), $\mathrm{HCl}$ (Merck, >35\%), NaOH (Aldrich, $>97 \%$ ), $\mathrm{K}_{4}\left[\mathrm{Fe}(\mathrm{CN})_{6}\right] .3 \mathrm{H}_{2} \mathrm{O}$ (Merck, $\left.99 \%\right), \mathrm{K}_{3}\left[\mathrm{Fe}(\mathrm{CN})_{6}\right] .3 \mathrm{H}_{2} \mathrm{O}$ (Merck, $99 \%$ ), $\mathrm{KNO}_{3}$ (Merck, >98\%), Ascorbic Acid (SRL, 99.7 \%), Uric Acid (SRL, $99 \%$ ), D-Glucose (SRL, $99 \%$ ), Dopamine Hydrochloride (Alfa Aesar, $99 \%$ ), $\mathrm{KCl}$ (SRL, >99.5\%), $\mathrm{NaCl}$ (AR, ACS, ExiPlus, $99.9 \%$ ) and $\mathrm{Na}_{2} \mathrm{SO}_{4}$ (AR, ACS, ExiPlus, $99.9 \%$ ) were of analytical grade and used as received. The phosphate buffer solution (PBS, $0.1 \mathrm{M}$ ) was freshly prepared using $1 \mathrm{M}$ of $\mathrm{K}_{2} \mathrm{HPO}_{4}$ and $1 \mathrm{M}$ of $\mathrm{KH}_{2} \mathrm{PO}_{4}$ with triple distilled water. Prior to analysis, $10 \mathrm{~mL}$ of $0.1 \mathrm{M}$ PBS was purged with argon for 15 minutes to dissolved oxygen. The $\mathrm{pH}$ of $0.1 \mathrm{M}$ PBS was adjusted using either $5 \mathrm{M} \mathrm{HCl}$ or $5 \mathrm{M} \mathrm{NaOH}$. Stock solutions of $0.02 \mathrm{M}$ uric acid, $0.1 \mathrm{M}$ ascorbic acid and $0.01 \mathrm{M}$ dopamine were freshly prepared using $0.1 \mathrm{M} \mathrm{PBS}(\mathrm{pH} 7.0)$.

\section{Electrochemical measurements}

Differential pulse voltammetry (DPV), chronoamperometry (CA), cyclic voltammetry (CV) and electrochemical impedance spectroscopy (EIS) were carried out using conventional three-electrode assembly in the CHI660A electrochemical workstation ( $\mathrm{CH}$ instruments, USA). The pencil graphite leads (HB, $0.5 \mathrm{~mm}$ diameter, $60 \mathrm{~mm}$ height, Camlin), Pt gauze and saturated calomel electrode (SCE) were used as working, counter and reference electrodes, respectively.

\section{Anodization of PGE}

Prior to the anodization, PGEs were mechanically polished with a clean white paper (75 GSM grade) and washed thoroughly with water. An apparent surface area of $0.19 \mathrm{~cm}^{2}$ of PGE was exposed and the remaining area was covered using a scotch tape except a small portion exposed for connecting the leads. PGEs were anodized by CA and the experimental parameters such as anodization potential, time and supporting electrolyte were optimized for maximum sensing performance. As the first step, three different supporting electrolytes, namely 0.1 M PBS (pH 7.0), $0.1 \mathrm{M} \mathrm{HCl}(\mathrm{pH} 1.1)$ and $0.1 \mathrm{M} \mathrm{NaOH}(\mathrm{pH}$ 13.0) were used for anodization of PGEs at $2.0 \mathrm{~V}$ for $120 \mathrm{~s}$. Secondly, five different anodization potentials (1.6, 1.8, 2.0, 2.2 and $2.4 \mathrm{~V}$ ) and time applied (60, 120, 180, 240 and $300 \mathrm{~s})$ for anodization were examined in 0.1 M PBS (pH 7.0). PGE anodized at $2 \mathrm{~V}$ for $120 \mathrm{~s}$ in $0.1 \mathrm{M} \mathrm{PBS}$ (pH 7.0), was chosen as the optimized condition (vide infra) for anodization and the electrode hereafter will be referred as anodized PGE (APGE). These APGEs were then thoroughly washed with water, dried and subsequently used as working electrodes for further studies.

\section{Spectroscopic, morphological and electrochemical characterizations}

Fourier transform infrared (FT-IR) and Fourier transform Raman (FT-Raman) spectroscopies were used to characterize the electrodes. FT-IR spectra were recorded with the help of $\mathrm{KBr}$ pellets in JASCO 4100 spectrometer. In order to make the pellets, $0.5 \mathrm{~cm}$ of PGE (bare/anodized) was broken and grinded along with $\mathrm{KBr}$. Raman spectra were acquired using BRUKER RFS 27: Standalone FTRaman Spectrometer. The surface morphology (SEM) and electron dispersive analysis of X-rays 
(EDX) of both electrodes were carried out using FEI Quanta FEG200 at an acceleration voltage of 20 $\mathrm{kV}$ in high vacuum mode. Prior to the spectroscopic and morphological measurements, the electrodes were dried using a heat gun and stored in a vacuum desiccator for 48 hours to remove the moisture.

The electrochemical characterizations of PGE and APGE were carried out in $0.1 \mathrm{M} \mathrm{PBS}(\mathrm{pH} 7.0)$ solution containing $10 \mathrm{mM}\left[\mathrm{Fe}(\mathrm{CN})_{6}\right]^{4-/ 3-}(1: 1)$ using $\mathrm{CV}$ and EIS. For $\mathrm{CV}$, the potential was scanned from -0.2 to $0.6 \mathrm{~V}$ at different scan rates ( 5 to $50 \mathrm{mV} / \mathrm{s}$ ). EIS measurements were carried out at $0.26 \mathrm{~V}$ in the frequency range of $10^{4}$ to $10^{-1} \mathrm{~Hz}$ with the amplitude of $5 \mathrm{mV}$. The electrical equivalent circuit fittings were carried out using the default fitting software provided with the instrument.

Simultaneous detection of DA \& UA in the presence of high concentration of $A A$

The simultaneous detection of DA and UA at APGE was carried out in $0.1 \mathrm{M} \mathrm{PBS} \mathrm{(pH} \mathrm{7.0)} \mathrm{using} \mathrm{DPV}$ in the presence of $2 \mathrm{mM}$ of AA. DPV experiments for sensing were carried out by scanning the potential from -0.2 to $0.6 \mathrm{~V}$, while the other parameters such as increment voltage, amplitude, pulse width, pulse period and quiet time were kept constant at $0.004 \mathrm{~V}, 0.05 \mathrm{~V}, 0.05 \mathrm{~s}, 0.5 \mathrm{~s}$ and $2 \mathrm{~s}$, respectively. The corresponding calibration plots were constructed after triplicate measurements.

\section{Real sample analysis}

For real sample analysis, the human blood serum and urine samples were obtained from the Apollo clinical laboratory, IIT-Madras, Chennai. Blood serum and urine samples were respectively diluted to 500 and 1000 times in 0.1 M PBS (pH 7.0) prior to the measurement.

\section{Results and discussion}

\section{Spectroscopic characterization}

It is a well-established fact that anodization of carbon surface leads to the creation of surface defects due to the formation of oxygen rich functional groups such as $-\mathrm{COOH},-\mathrm{OH}$, etc. $[27,40]$. As a result, $\mathrm{sp}^{2}$ hybridized lattices of graphite get distorted because of $\mathrm{sp}^{3}$ hybridized carbons of these functional groups. The changes such as formation of new functional groups and distortion of graphite lattice sites are effectively captured in FT-IR and FT-Raman spectroscopy, respectively. Infrared spectroscopy is an excellent tool for finding out the formation of new functional groups. FT-IR spectra for PGE before and after anodization process in $0.1 \mathrm{M} \mathrm{PBS}(\mathrm{pH} 7.0)$ are given in Figure 1a.
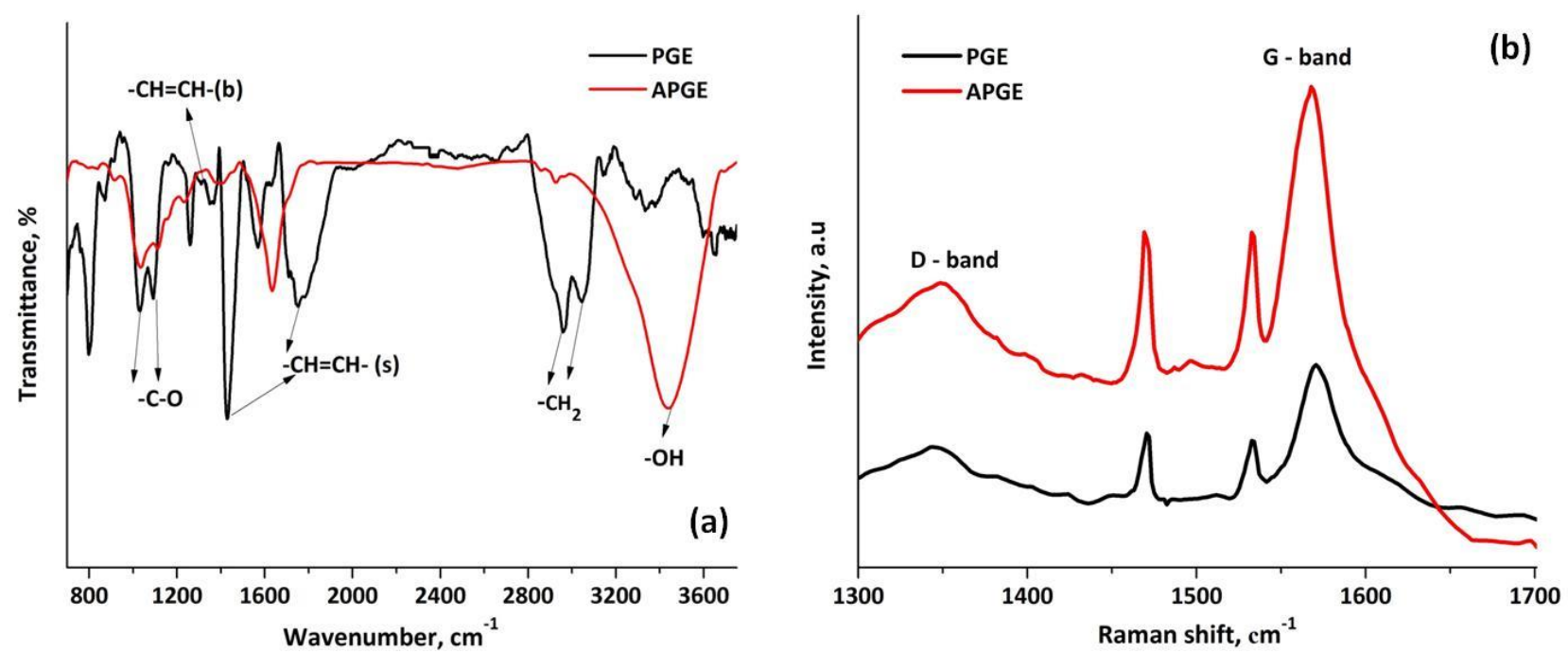

Figure 1. (a) FT-IR and (b) FT Raman spectra for PGE and APGE 
It can be inferred from Figure 1a that oxygen rich functional groups have formed on PGE as a result of anodization. The characteristic peaks at $3144 \mathrm{~cm}^{-1}(\mathrm{O}-\mathrm{H}$ stretching from $\mathrm{COOH}), 1662 \mathrm{~cm}^{-1}$ ( $\mathrm{C}=\mathrm{C}$ stretching), $1394 \mathrm{~cm}^{-1}$ ( $\mathrm{C}=\mathrm{C}$ bending) and $1088 \mathrm{~cm}^{-1}(\mathrm{C}-\mathrm{O}$ stretching from $\mathrm{COOH}$ ) indicate the successful modification of PGE surface with these functional groups $[41,42]$. Furthermore, IR peak intensities of APGE are significantly higher than that of PGE. It can be inferred from Figure 1a that oxygen rich functional groups have formed on PGE as a result of anodization. The characteristic peaks at $3144(\mathrm{O}-\mathrm{H}$ stretching from $\mathrm{COOH}), 1662$ ( $\mathrm{C}=\mathrm{C}$ stretching), 1394 ( $\mathrm{C}=\mathrm{C}$ bending) \& $1088 \mathrm{~cm}^{-1}$ ( $\mathrm{C}-\mathrm{O}$ stretching from $\mathrm{COOH}$ ) indicate the successful modification of PGE surface with these functional groups $[41,42]$. Also, IR peak intensities of APGE are significantly higher than that of PGE.

In order to investigate the variations in the graphitic structures, Raman spectroscopy is the characterization tool of choice. Once the graphitic lattice is altered after anodization, they exhibit characteristic $D$ and $G$ vibrational bands at wavenumbers $\sim 1330 \mathrm{~cm}^{-1}$ for $\mathrm{sp}^{3}$ hybridized (disordered, tetragonal) and $\sim 1570 \mathrm{~cm}^{-1}$ for $\mathrm{sp}^{2}$ hybridized (ordered, hexagonal) carbons present in them. Furthermore, the ratio of intensities of $\mathrm{D}$ band to $\mathrm{G}$ band i.e., $I_{\mathrm{D}} / I_{\mathrm{G}}$ provides a measure of the disorderliness present in the graphite lattice [43]. Moreover, greater $I_{\mathrm{D}} / I_{\mathrm{G}}$ value is an indication of more disorderliness. In general, it has been reported that the oxygen rich functional groups such as quinone, phenol and alcohols are responsible for $D$ band of oxygen containing graphitic materials [41,44-47]. Figure $1 b$ depicts Raman spectra for PGE and APGE which show D and G bands at 1351 and $1569 \mathrm{~cm}^{-1}$, respectively. Moreover, $I_{D} / I_{G}$ was observed to be 0.589 and 0.594 for PGE and APGE, respectively. Hence, it is evident from $I_{D} / I_{G}$ ratios for PGE and APGE that, APGE exhibits more disorderliness due to anodization.

\section{Morphological characterization}

The morphological variations of PGEs after anodization were analyzed using SEM technique. SEM images for PGE and APGE are shown in Figures $2 a \& 2 b$, respectively. It can be inferred from Figure 2 that the roughness of the graphite surface has significantly increased after anodization. Furthermore, the formation of oxygen containing groups after anodization is further corroborated from the presence of oxygen elemental peak in EDX spectrum for APGE (Figure 2d) which is absent for PGE (Figure 2c).

\section{Electrochemical characterization}

Electrochemical behaviors of PGE and APGE were evaluated using the standard $\left[\mathrm{Fe}(\mathrm{CN})_{6}\right]^{3-/ 4-}$ redox couple and the cyclic voltammograms of both these electrodes are shown in Fig. 3a. Cyclic voltammograms recorded at different scan rates for APGE are shown in Figure 3b. In comparison with the voltammetric response of PGE, the peak current of APGE was found to be higher thereby indicating an enhanced electron transfer after anodization. Moreover, the peak currents of both PGE and APGE were found to increase with the scan rate. The electrochemical active surface areas (ECASA) for PGE and APGE were calculated from $i_{\mathrm{p}} v$ s. $v^{1 / 2}$ plots (Fig. $3 c$ ) using the Randles-Ševcik equation:

$$
i_{\mathrm{p}}=2.69 \times 10^{5} n^{3 / 2} D^{1 / 2} A C_{\mathrm{s}} v^{1 / 2}
$$

where $i_{\mathrm{p}}$ is the peak current in A, $n$ is the number of electrons in the redox process (here $n=1$ ), $D$ is the diffusion coefficient of $\left[\mathrm{Fe}(\mathrm{CN})_{6}\right]^{3-/ 4-}\left(1.32 \times 10^{-6} \mathrm{~cm}^{2} / \mathrm{s}\right), C_{\mathrm{s}}$ denotes the bulk concentration of $\left[\mathrm{Fe}(\mathrm{CN})_{6}\right]^{3-/ 4-}(10 \mathrm{mM}, 1: 1)$ and $v$ is the scan rate. The parameter $A$ in equation (1) denotes ECASA that was found to be $0.36 \mathrm{~cm}^{2}$ and $1.32 \mathrm{~cm}^{2}$, respectively, for PGE and APGE. Furthermore, the roughness factors for PGE and APGE were determined using ECASA to geometrical surface area ratio which was estimated to be 1.78 and 6.48 , respectively. This considerable increase in the roughness of APGE is in concordance with the observations in SEM micrographs (Figure $2 \mathrm{~b}$ ). 

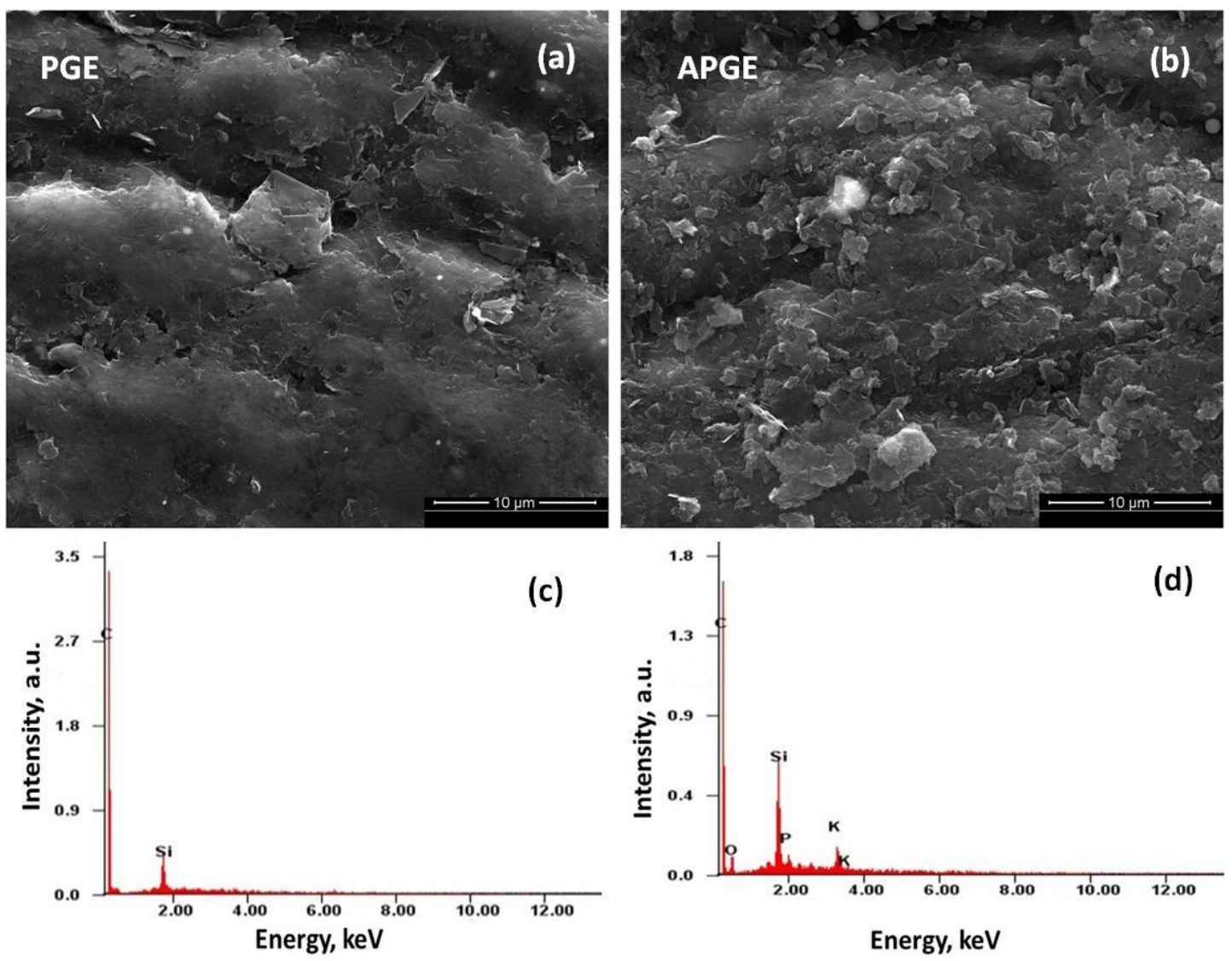

Figure 2. Scanning electron micrographs for (a) PGE and (b) APGE.

The corresponding EDX spectra for (c) PGE and (d) APGE
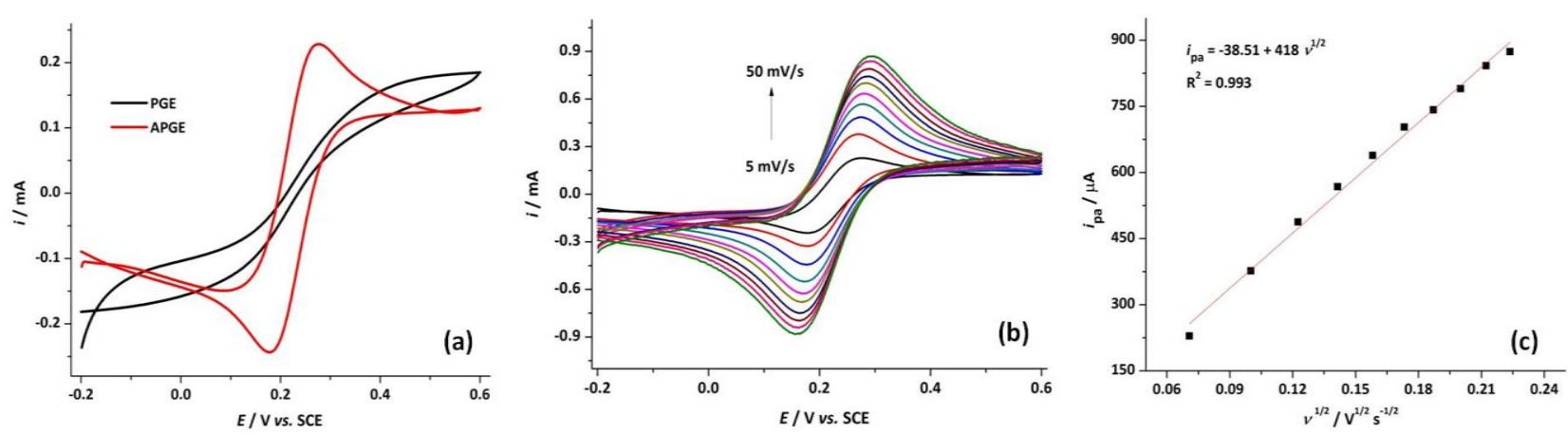

Figure 3. Cyclic voltammograms in $0.1 \mathrm{M} \mathrm{PBS}(\mathrm{pH} 7.0)$ containing $10 \mathrm{mM}(1: 1)\left[\mathrm{Fe}(\mathrm{CN})_{6}\right]^{3-14}$-for (a) APGE and $P G E$ at $5 \mathrm{mV} / \mathrm{s}$, and (b) APGE at various scan rates ranging from $5 \mathrm{mV} / \mathrm{s}$ to

$50 \mathrm{mV} / \mathrm{s}$. (c) Variation of $i_{p a}$ with $v^{1 / 2}$ for APGE

In order to understand the variation in the electron transfer kinetics of PGE before and after anodization, EIS was employed. Nyquist plots measured for PGE and APGE in 0.1 M PBS (pH 7.0) containing $10 \mathrm{mM}(1: 1)\left[\mathrm{Fe}(\mathrm{CN})_{6}\right]^{3-/ 4-}$ at $0.26 \mathrm{~V}$ are shown in Figure 4a. The distinct semicircular shape in the Nyquist plot for APGE at higher to medium frequencies corresponds to the electron transfer limited process while the linear part extending to lower frequencies indicates the process limited by diffusion. Nyquist plot of PGE, however, exhibits a prominent semicircular shape without a contribution of linear part due to diffusion impedance. The Nyquist plots obtained were fitted using modified Randles electrical equivalent circuits shown in Figures $4 \mathrm{~b}$ and $4 \mathrm{c}$, respectively for PGE and APGE. The constant phase element (CPE) was chosen as double-layer capacitive element to account for various inhomogeneities arising from the nature of the electrode and its porosity [48]. Warburg element $(W)$ denotes impedance due to diffusion, while $R_{\mathrm{s}}$ and $R_{\mathrm{ct}}$ denote resistances due to the electrolyte solution and charge transfer at the electrode-electrolyte interface, respectively. 
Frequency dependences of CPE impedance $\left(Z_{\mathrm{CPE}}\right)$ and Warburg impedance $\left(Z_{\mathrm{W}}\right)$ are defined as:

$$
\begin{aligned}
& \frac{1}{Z_{\mathrm{CPE}}}=C P E_{\mathrm{dl}}(j \omega)^{n_{\mathrm{dl}}} \\
& Z_{w}=\frac{\omega^{-0.5}}{W}(1-j)
\end{aligned}
$$
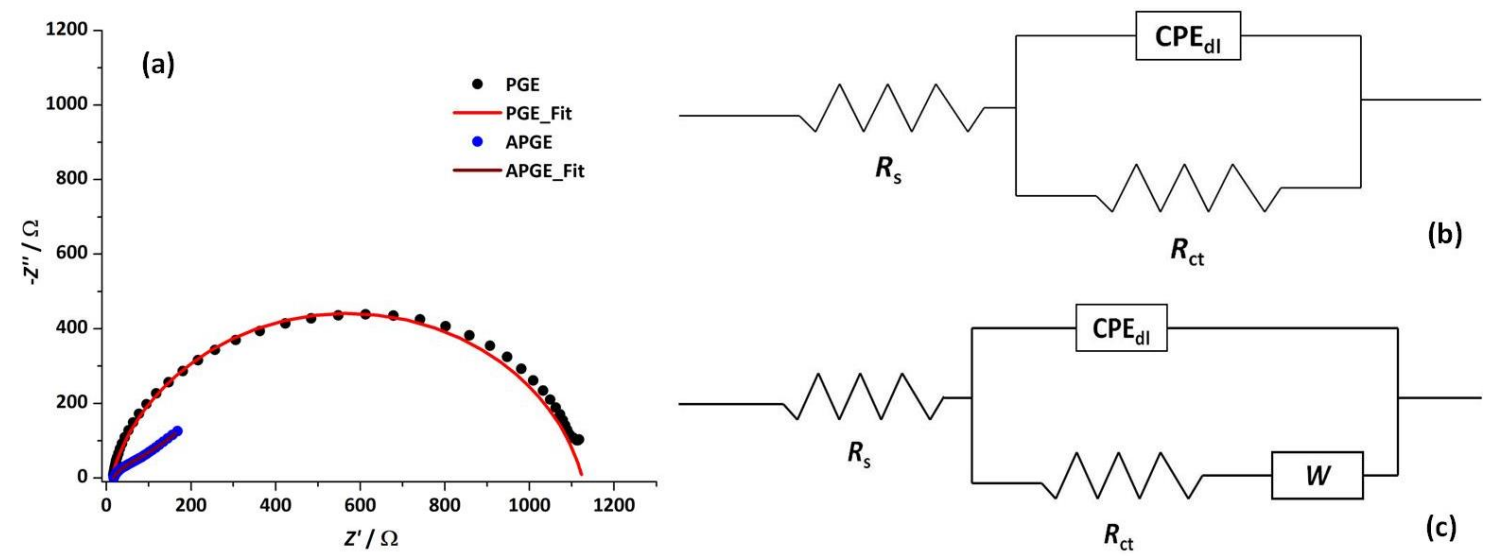

Figure 4. (a) Nyquist plots for PGE and APGE measured in $0.1 \mathrm{MPBS}(\mathrm{pH} 7.0)$ containing $10 \mathrm{mM}\left[\mathrm{Fe}(\mathrm{CN})_{6}\right]^{4-/ 3-}$ $(1: 1)$ at $0.26 \mathrm{~V}$ in the frequency range of $10^{4}$ to $10^{-1} \mathrm{~Hz}$. Electrical equivalent circuits for (b) PGEand (c) APGE

In equations (2) and (3), $\mathrm{CPE}_{\mathrm{dl}}, n_{\mathrm{dl}}$ and $W$ are frequency independent impedance parameters, while $\mathrm{j}$ is imaginary number and $\omega$ is radial frequency of measurements. Impedance parameter values obtained by fitting electrical equivalent circuits to the Nyquist plots are given in Table 1.

Table 1. Summary of impedance parameter values obtained by fitting equivalent circuits in Figure $4 b-c$ to Nyquist plots in Figure $4 a$

\begin{tabular}{ccccccc}
\hline Electrode & $R_{\mathrm{s}} / \Omega$ & $\mathrm{CPE}_{\mathrm{dl}}, \mu \mathrm{S} \mathrm{s}^{n}$ & $n_{\mathrm{dl}}$ & $W / \mathrm{S} \mathrm{s}^{1 / 2}$ & $R_{\mathrm{ct}} / \Omega$ & $k_{\mathrm{o}} / 10^{-6} \mathrm{~cm} \mathrm{~s}^{-1}$ \\
\hline PGE & 11.92 & 11.64 & 0.854 & -- & 1113 & 6.64 \\
\hline APGE & 16.91 & 226.9 & 0.713 & 0.007 & 100.8 & 19.99 \\
\hline
\end{tabular}

From the charge transfer resistance $\left(R_{\mathrm{ct}}\right)$ values, the standard heterogeneous rate constants $\left(k_{\mathrm{o}}\right)$ were estimated using equation (4) and are provided in Table 1:

$$
k_{\mathrm{o}}=\frac{R T}{n^{2} F^{2} A R_{\mathrm{ct}} C_{\mathrm{s}}}
$$

It can be inferred from Table 1 that $k_{\mathrm{o}}$ for APGE is 3 times higher than for PGE which in turn is responsible for its enhanced electrochemical activity (vide infra).

\section{Electrochemical behavior of APGE towards DA and UA}

In order to compare the performance of PGE and APGE towards DA and UA detection, voltammetric techniques were employed. The cyclic voltammetric responses of $10 \mu \mathrm{M}$ DA (Figure $5 \mathrm{a}$ ) and $20 \mu \mathrm{M}$ UA (Figure 5c) were recorded in $0.1 \mathrm{M} \mathrm{PBS}(\mathrm{pH} \mathrm{7.0)}$ ) at the scan rate of $25 \mathrm{mV} / \mathrm{s}$. It can be inferred from Figures $5 a \& 5 c$ that quasi reversible behavior was observed for both DA \& UA at APGE. On the other hand, at PGE, an irreversible cyclic voltammogram was observed for both species. Furthermore, the anodic peak at APGE for DA and UA was found to be centered at $0.15 \mathrm{~V}$ and $0.33 \mathrm{~V}$, respectively. Also, the corresponding current responses at APGE for DA and UA were 12 and 10 times higher than at PGE. 

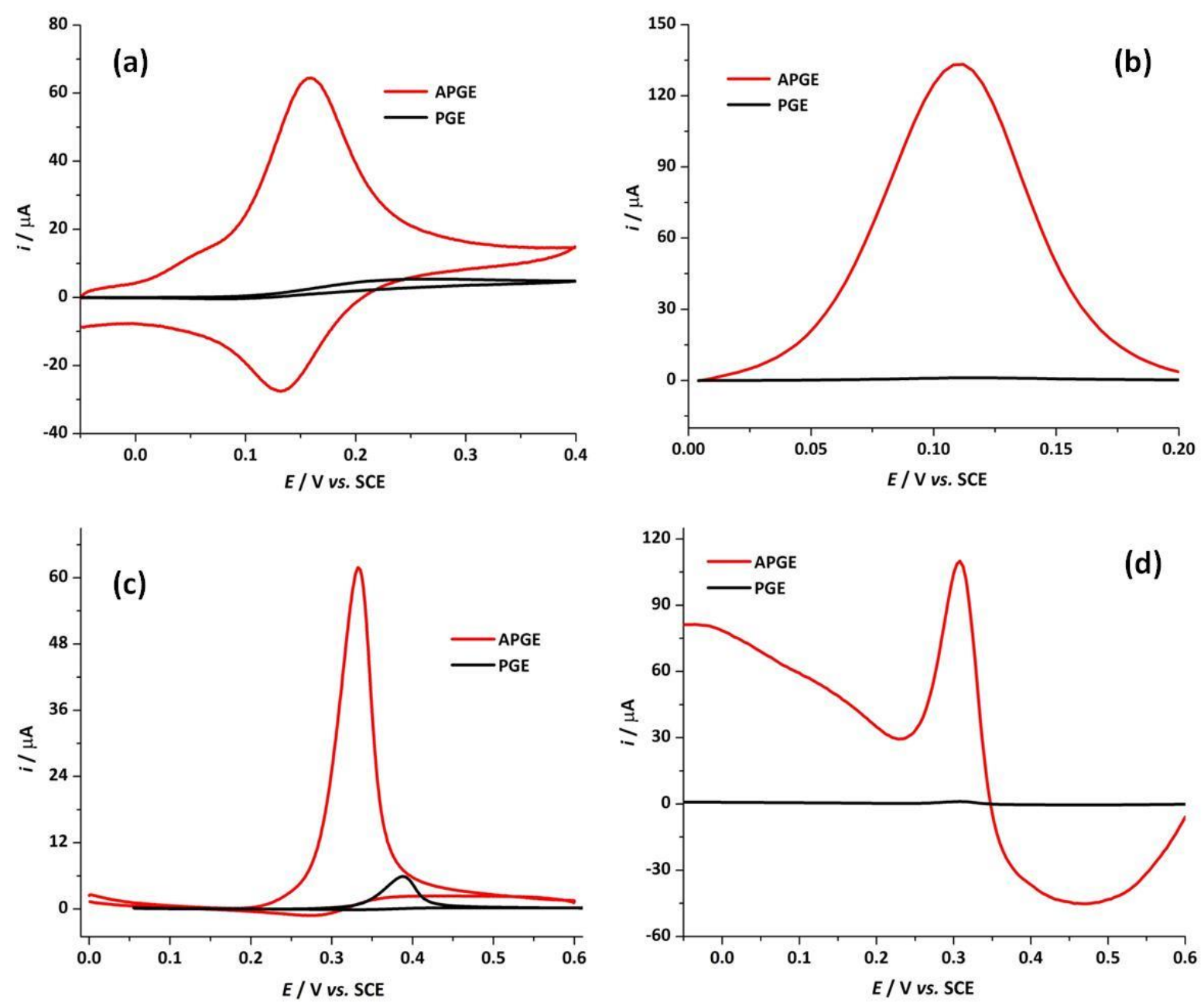

Figure 5. Cyclic voltammograms of (a) $10 \mu \mathrm{M}$ of DA and (c) $20 \mu \mathrm{M}$ of UA in $0.1 \mathrm{M}$ PBS (pH 7.0) at PGE and APGE. Corresponding differential pulse voltammograms for (b) DA and (d) UA

Since differential pulse voltammetry (DPV) is known to be more sensitive analytical technique than CV, DPV responses for DA (Fig. 5b) and UA (Fig. 5d) at APGE were compared with PGE. At APGE, the oxidation peak potential was observed at $0.11 \mathrm{~V}$ for DA and $0.31 \mathrm{~V}$ for UA. However, extremely weak DPV signals for DA and UA oxidation were observed at PGE. Unlike CVs shown in Figs. 5a \& 5c, the oxidation peak currents in DPV for DA and UA at APGE were found 92 and 112 times higher than at PGE (Figs. 5b \& 5d). The enhanced current response for DA and UA at APGEis attributed to its increased ECASAand the presence of non-covalent interactions (vide infra). Thus, it is evident from the above discussion that APGE can be effectively employed for the detection of DA and UA.

\section{Effect of $\mathrm{pH}$}

The effect of $\mathrm{pH}$ of PBS on the detection of DA and UA was investigated using DPV in the $\mathrm{pH}$ range of 5.0 - 9.0 and the corresponding voltammograms are shown in Figures $6 a \& 6 \mathrm{c}$. The anodic peak currents of both DA and UA increase, reach the maximum at $\mathrm{pH} 7.0$, and for higher $\mathrm{pH}$ decrease subsequently. The increment in the peak currents from pH 5.0 to 7.0 is attributed to the proton transfer during the oxidation process. On the other hand, the decrease in the peak currents from $\mathrm{pH} 7.0$ to 9.0 is due to the facile oxidation of hydroxyl groups and the instability of the oxidized form of DA and UA [49].

Furthermore, the oxidation peak potentials $\left(E_{\mathrm{p}}\right)$ of DA and UA were found to be dependent on $\mathrm{pH}$ values as observed in Figures $6 \mathrm{~b} \& 6 \mathrm{~d}$. It can also be deduced from these figures that with every 
unit increase of $\mathrm{pH}$, the $E_{\mathrm{p}}$ shifts towards negative potential region. The linear regression equation for the dependence of $E_{\mathrm{p}}$ with $\mathrm{pH}$ agrees with the Nernst equation viz.

$$
E_{\mathrm{p}}=E^{\mathrm{O}}-0.0591 \mathrm{pH}
$$

where $E^{0 \prime}$ is the formal potential. Since the slope values observed here for $\mathrm{DA}(-60.4 \mathrm{mV} / \mathrm{pH})$ and UA $(-58.6 \mathrm{mV} / \mathrm{pH})$ are in close agreement with the theoretical slope value of equation (5), the same number of electrons and protons is involved in the oxidation process. The electrochemical oxidation of DA and UA taking place at APGE is illustrated in Scheme 1. Based on the highest current response, $\mathrm{pH} 7.0$ has been chosen as the optimized $\mathrm{pH}$ for subsequent experiments.
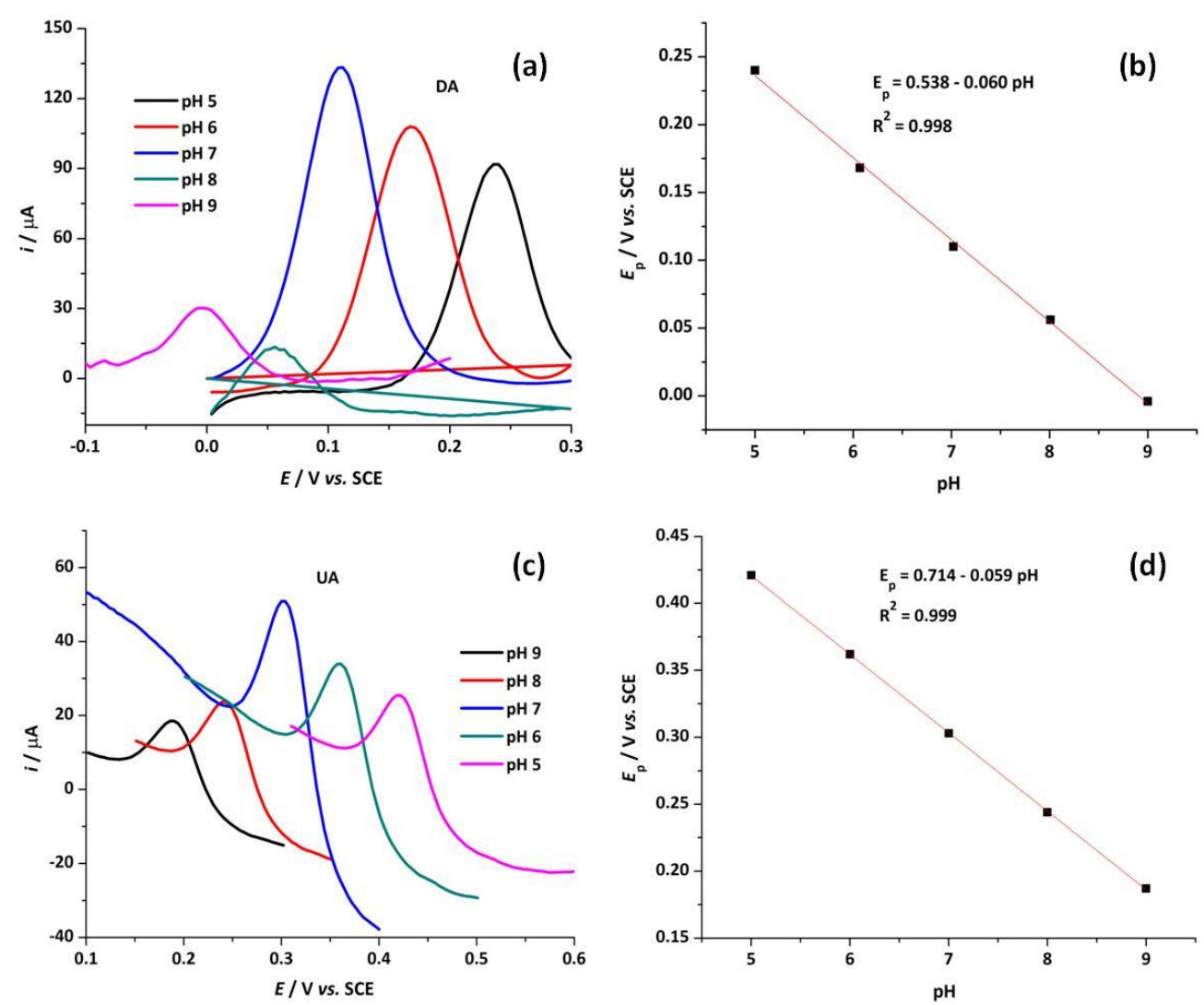

Figure 6. Differential pulse voltammograms of APGE at different $p H$ values in $0.1 \mathrm{M} P B S$ containing (a) $10 \mu \mathrm{M}$ of $D A$ and (c) $20 \mu \mathrm{M}$ of UA. Variations in $E_{p}$ with change in $\mathrm{pH}$ for (b) DA and (d) UA

(a) Dopamine<smiles>NCCC1=CC(=O)C(=O)C=C1</smiles>

(b) Uric Acid<smiles>O=c1[nH]c(=O)c2[nH]c(=O)[nH]c2[nH]1</smiles><smiles>C=C[I+]</smiles>

Scheme 1. Schematic representation of electrochemical oxidation mechanism of DA and UA at APGE 


\section{Optimization of experimental parameters}

Prior to the simultaneous determination of DA and UA at APGE, various experimental parameters such as kind of supporting electrolyte, potential and time used for anodization were analyzed via DPV current responses of various APGEs in solutions containing $20 \mu \mathrm{M}$ of either DA or UA. Before optimizing the anodization potential and time, the effects of supporting electrolytes were studied using $0.1 \mathrm{M} \mathrm{PBS}, 0.1 \mathrm{M} \mathrm{NaOH}$ and $0.1 \mathrm{M} \mathrm{HCl}$ while the applied potential and time were kept constant at $2 \mathrm{~V}$ and $120 \mathrm{~s}$, respectively. The corresponding DPV responses are shown in Figure 7a for DA and Figure $7 \mathrm{~d}$ for UA. Since the maximum current response was observed in $0.1 \mathrm{M}$ PBS for both DA and $U A$, it was chosen as the supporting electrolyte in the subsequent studies.
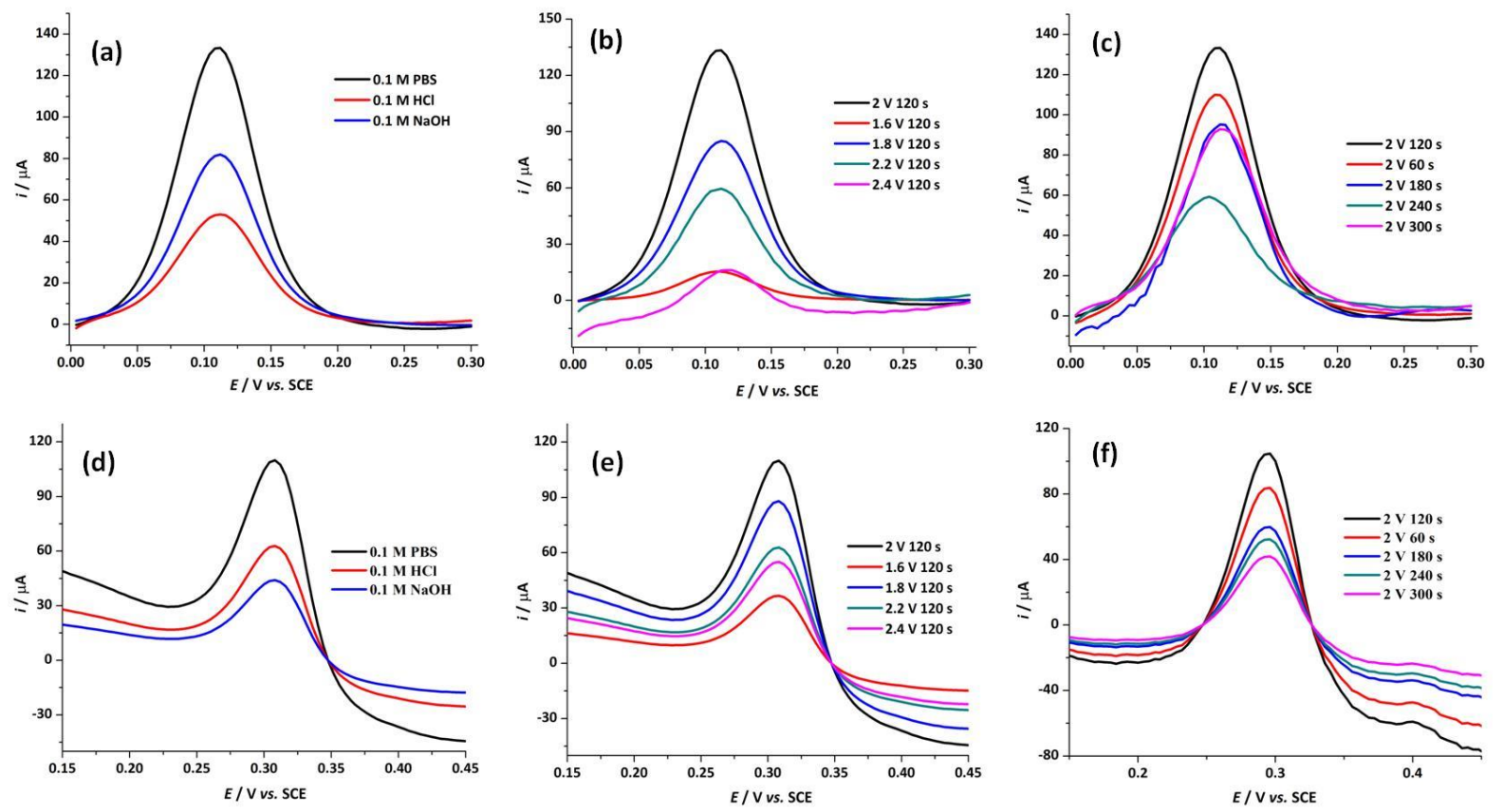

Figure 7. Differential pulse voltammograms for APGE prepared in $(a, d)$ different supporting electrolytes, and $(b, e)$ in $0.1 \mathrm{M}$ PBS ( $p H$ 7.0) at different applied anodization potentials and

$(c, f)$ different anodization times. Solutions contained(a-c) $20 \mu M$ of DA and (d-f) $20 \mu M$ of UA.

For optimizing the anodization potential, the time of anodization was kept constant at $120 \mathrm{~s}$ while the applied potential was varied from $1.6 \mathrm{~V}-2.4 \mathrm{~V}$ in $0.1 \mathrm{M}$ PBS. The maximum current response was observed for APGE anodized at $2 \mathrm{~V}$ in the case of both DA (Figure 7b) and UA (Figure 7e). Furthermore, the anodization time was optimized by varying the time of anodization from $60-300 \mathrm{~s}$, while keeping the anodization potential constant at $2 \mathrm{~V}$. The maximum current response was observed for APGE anodized at $2 \mathrm{~V}$ for $120 \mathrm{~s}$ for both DA (Figure 7c) and UA (Figure 7f). DPV results depicted in Figure 7 can be understood as follows: due to severe anodization in basic solution $(0.1 \mathrm{M} \mathrm{NaOH})$, more oxygen containing functional groups may form, thereby resulting in sluggish electron transfer. On the other hand, the extent of anodization is comparatively lower in acidic condition $(0.1 \mathrm{M} \mathrm{HCl})$ which results in poor current response for the oxidation of DA and UA. However, in neutral conditions optimal surface oxidation of graphite occurs which in turn is responsible for the maximum current response. At higher anodization potential or time, the graphite surface gets oxidized excessively. This leads to low current response for DA and UA. On the contrary, due to insufficient formation of oxygen containing functional groups at lower anodization potential or time, the current observed in voltammograms for DA and UA oxidation is poor. Thus, from the maximum current responses observed in Figures 7a-f, the optimized conditions for anodization potential, anodization time and supporting electrolyte were chosen as $2 \mathrm{~V}$, $120 \mathrm{~s}$ and $0.1 \mathrm{M}$ PBS (pH 7.0), respectively. 


\section{Mechanistic investigation of DA and UA oxidation at APGE}

The effect of scan rate $(v)$ changes was investigated at APGE in $0.1 \mathrm{M} \mathrm{PBS}(\mathrm{pH} 7.0)$ containing either $100 \mu \mathrm{M}$ of DA (Figure 8a) or UA (Figure 9a) by varying scan rates from 5 to $500 \mathrm{mV} / \mathrm{s}$. The logarithm of peak currents ( $\left.\log i_{\mathrm{pa}}\right)$ of DA and UA increases linearly with logarithm of scan rate $(\log v)$ (Figures $8 b$ \& 9b) suggesting that the redox processes taking place at APGE may be adsorption or diffusion controlled [50]. Furthermore, an excellent linearity between $\log i_{\text {pa }}$ and $\log v$ with the slope value close to unity for DA (Figure $8 b$ ) and 0.5 for UA (Figure 9b) was observed. These slope values indicate that adsorption and diffusion-controlled electron transfer process is predominant for DA and UA, respectively.
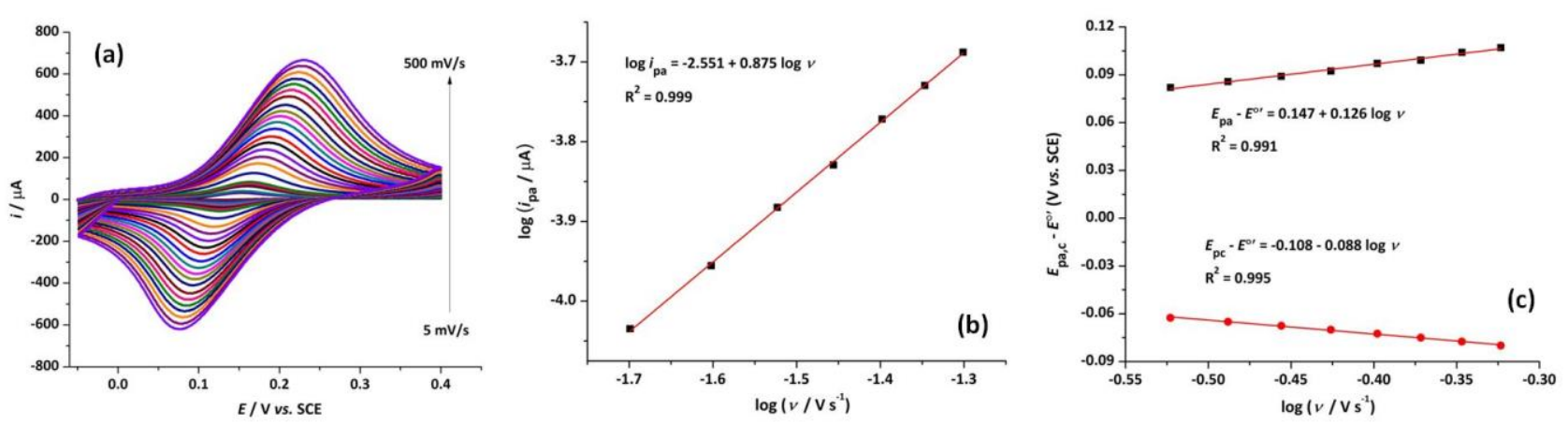

Figure 8.(a)Cyclic voltammograms of APGE electrodes containing $100 \mu \mathrm{M}$ DA in $0.1 \mathrm{M} \mathrm{PBS}$ (pH 7.0) at scan rates ranging from $5-500 \mathrm{mV} / \mathrm{s},(b)$ variation of $\log \mathrm{i}_{p a}$ with $\log \mathrm{v}$, and variation of $\mathrm{E}_{p}-\mathrm{E}^{\circ \prime}$ with $\log \mathrm{v}$
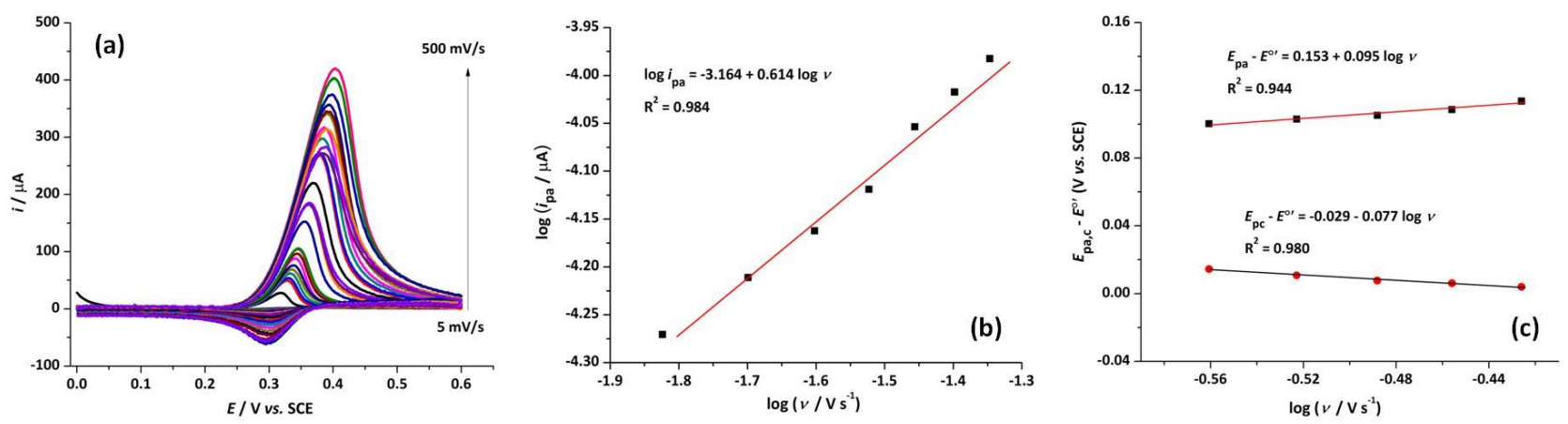

Figure 9. (a) Cyclic voltammograms of APGE electrodes containing $100 \mu M U A$ in $0.1 \mathrm{M} P B S(p H 7.0)$ at scan rates ranging from $5-500 \mathrm{mV} / \mathrm{s}$, (b) variation of $\log \mathrm{i}_{p a}$ with $\log \mathrm{v}$, and variation of $\mathrm{E}_{p}-\mathrm{E}^{\circ \prime}$ with $\log \mathrm{v}$

According to Laviron's formalism [51,52], when $\Delta E_{\mathrm{p}}>(0.20 / \mathrm{n}) \mathrm{V}$, a linear plot of $E_{\mathrm{p}(\mathrm{a}, \mathrm{c})} E^{-\mathrm{o}^{\prime}}$ vs. $\log v$ would be observed. Furthermore, from the intercepts of $E_{\mathrm{p}(a, c)}-E^{\prime \prime} v s$. log $v$ plots, the electron transfer coefficient $(\alpha)$ and the apparent surface electron transfer rate constant $\left(k_{s}\right)$ can be obtained using the following equations:

$$
\begin{aligned}
& \frac{v_{\mathrm{a}}}{v_{\mathrm{c}}}=\frac{\alpha}{1-\alpha} \\
& k_{\mathrm{s}}=\frac{(1-\alpha) n F v_{\mathrm{a}}}{R T}=\frac{\alpha n F v_{\mathrm{c}}}{R T}
\end{aligned}
$$

In equations (6) and (7), $v_{a}$ and $v_{c}$ denote the intercepts for anodic and cathodic process, respecttively, $n$ is the number of electrons involved in the redox process, while other symbols have their usual significance. Here, $E^{\prime \prime}$ corresponds to the formal potential or the mean value of the anodic and cathodic peak potentials obtained at $5 \mathrm{mV} / \mathrm{s}$. The number of electrons $(n)$ involved in the redox process was calculated to be 2.01 and 1.55 for DA and UA respectively, using equation (8) at $5 \mathrm{mV} / \mathrm{s}$. 


$$
\Delta E_{\mathrm{p}}=\frac{0.059}{n}
$$

From Figures $8 \mathrm{c} \& 9 \mathrm{c}$, an excellent linearity between $E_{\mathrm{p}(\mathrm{a}, \mathrm{c})}-E^{\mathrm{O}^{\prime}}$ and $\log \mathrm{v}$ can be evidenced for DA and UA, respectively. The values calculated using equations (6-8) are summarized in Table 2 . It can be deduced from Table 2 that $k_{s}$ for DA is higher than the value observed for poly(L-aspartic acid) modified GCE $\left(1.13 \mathrm{~s}^{-1}\right)$ [53]. On the other hand, $k_{\mathrm{s}}$ for UA is greater than the value found for modified carbon nanotube paste electrode $\left(1.17 \mathrm{~s}^{-1}\right)$ [54].

Table 2. Summary of kinetic parameters for DA and UA at APGE estimated from Laviron's theory

\begin{tabular}{ccc}
\hline Parameters & DA & UA \\
\hline$\alpha$ & 0.58 & 0.60 \\
\hline$n$ & 2.01 & 1.55 \\
\hline$k_{s} / \mathrm{cm} \mathrm{s}^{-1}$ & 4.87 & 3.69 \\
\hline
\end{tabular}

Selective determination of DA and UA at APGE in the presence of high concentration of ascorbic acid

Since ascorbic acid (AA)ispresent at high concentration levelsin human body fluids, it is imperative to carefully evaluate the ability of APGE to selectively determine DA and UA in the presence of AA. Moreover, it is the prime objective of the current study. The comparison of differential pulse voltammograms of DA, UA and AA measured separately and at mixtures are shown in Figure 10. It is evident from Figure 10 that APGE doesn't produce any signal for AA even if its concentration is high ( $2 \mathrm{mM}$ ). Thus, it is apparent from these voltammograms that APGE is able to detect DA and UA selectively without any interference from AA.

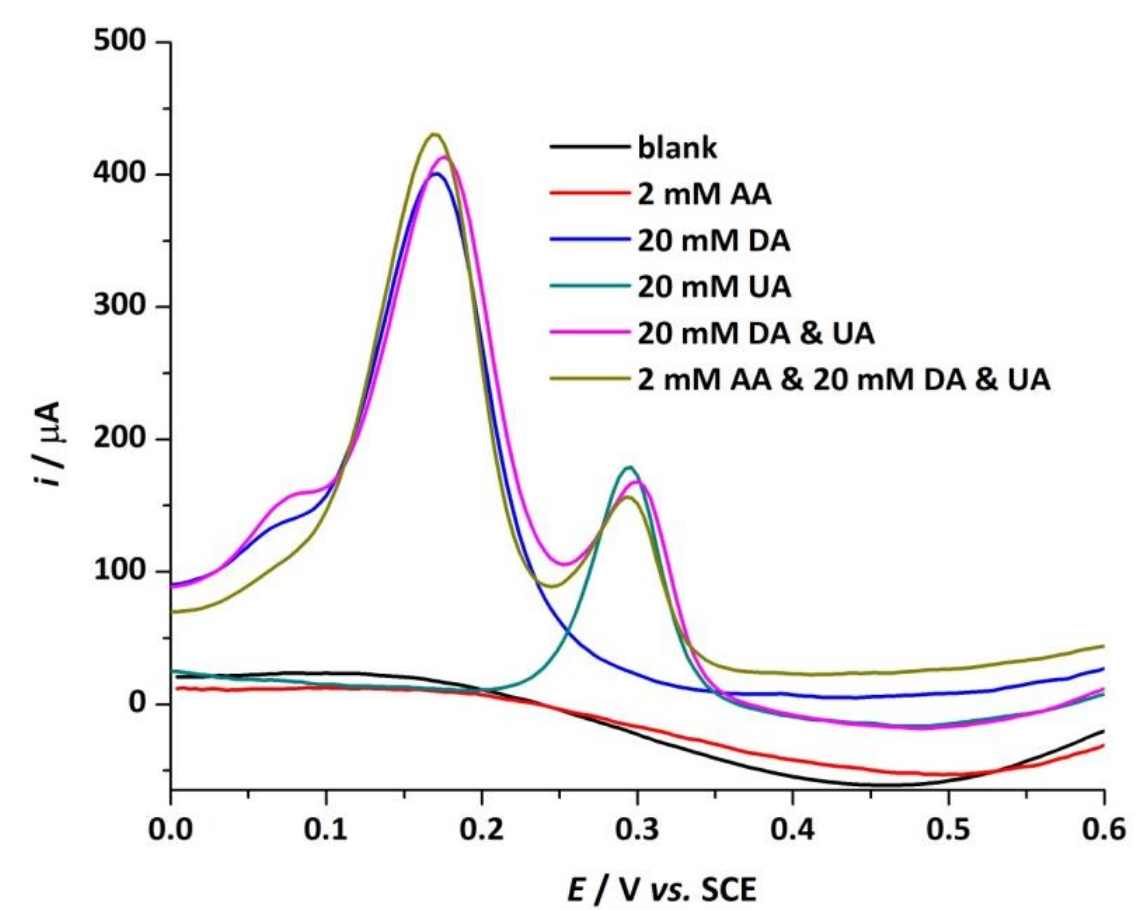

Figure 10. Comparison of various differential pulse voltammograms at APGE in $0.1 \mathrm{MPBS}(\mathrm{pH} 7.0)$ and denoted concentrations of $D A, U A$ and $A A$

The discriminating ability of APGE towards DA, UA and AA can be understood in the following way $[11,38,43]$. The anodization process creates negative surface charge on APGE due to the formation of oxygen rich functional groups. It is well known that DA and UA exist in their protonated forms at neutral or physiological $\mathrm{pH}$, while $\mathrm{AA}$ exists in deprotonated form. 
Furthermore, during the positive potential scan the negatively charged oxygen rich groups on APGE surface favor the formation of hydrogen bonds with both DA and UA. Since, the voltammetric current response for DA oxidation is higher than that of UA (Figure 10), there may be another non-covalent interaction like $\pi-\pi$ interaction in addition to the existing electrostatic and hydrogen bonding interactions between APGE and DA. On the other hand, the imperceptible voltammetric response observed for AA in Figure 10 is an indication of the absence of any such interactions between AA and APGE surface. The electrode mechanism described above is concisely summarized in Scheme 2.
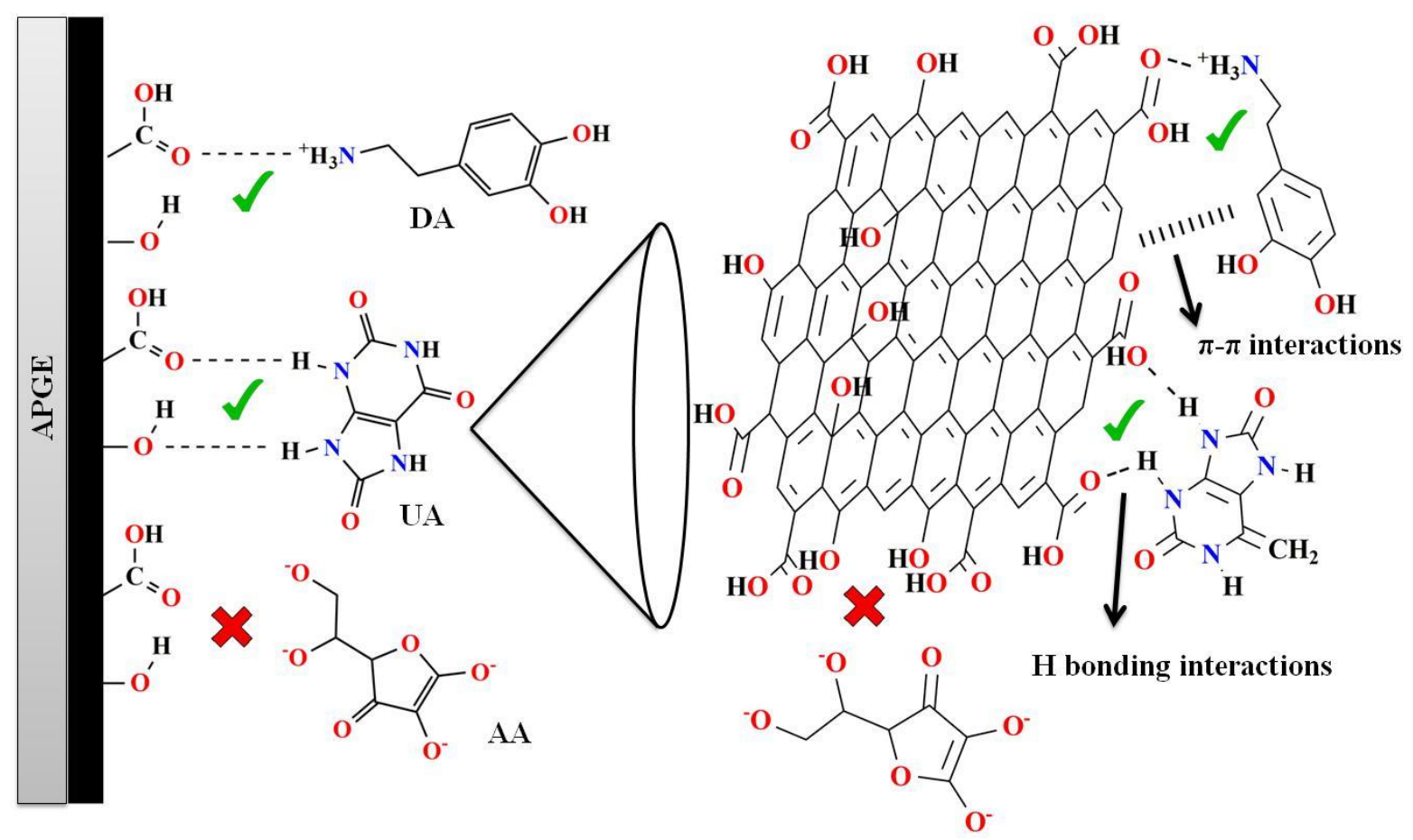

Scheme 2. Plausible mechanism for the selective detection of DA and UA in the presence of AA at APGE

\section{Simultaneous detection of DA and UA at APGE}

The main objective of this study was to evaluate the ability of APGE to simultaneously determine $D A$ and $U A$ in the presence of AA. In this regard, three differential pulse voltammetric experiments were carried out as follows: (i) $10 \mu \mathrm{M}$ of DA and $2 \mathrm{mM}$ of $\mathrm{AA}$ is kept constant while the concentration of UA is changed, (ii) $20 \mu \mathrm{M}$ of UA and $2 \mathrm{mM}$ AA is kept constant and the concentration of DA is varied, (iii) both DA and UA concentration is simultaneously altered in the presence of $2 \mathrm{mM}$ AA. The corresponding differential pulse voltammograms are given in Figures 11a-c. It can be inferred from Figures 11a-c that with the increase in the concentration of DA and UA, the peak currents increase linearly. Furthermore, the linear calibration plots constructed from these DPV responses are given in Figures $11 \mathrm{~d}$-f. On close inspection of these calibration plots, it can be deduced that, in all three cases two linear ranges were observed in the concentration regions of 1-10 $\mu \mathrm{M}$ and 20-50 $\mu \mathrm{M}$, respectively. The linearity observed in Figures $11 \mathrm{~d}$-f indicates the excellent ability of APGE to simultaneously determine DA and UA even in the presence of high concentration of AA without any cross interference.

The results obtained in the present study are compared in Table 3 with these obtained for other chemically modified carbon electrodes already reported in the literature for the simultaneous detection of DA and UA. 

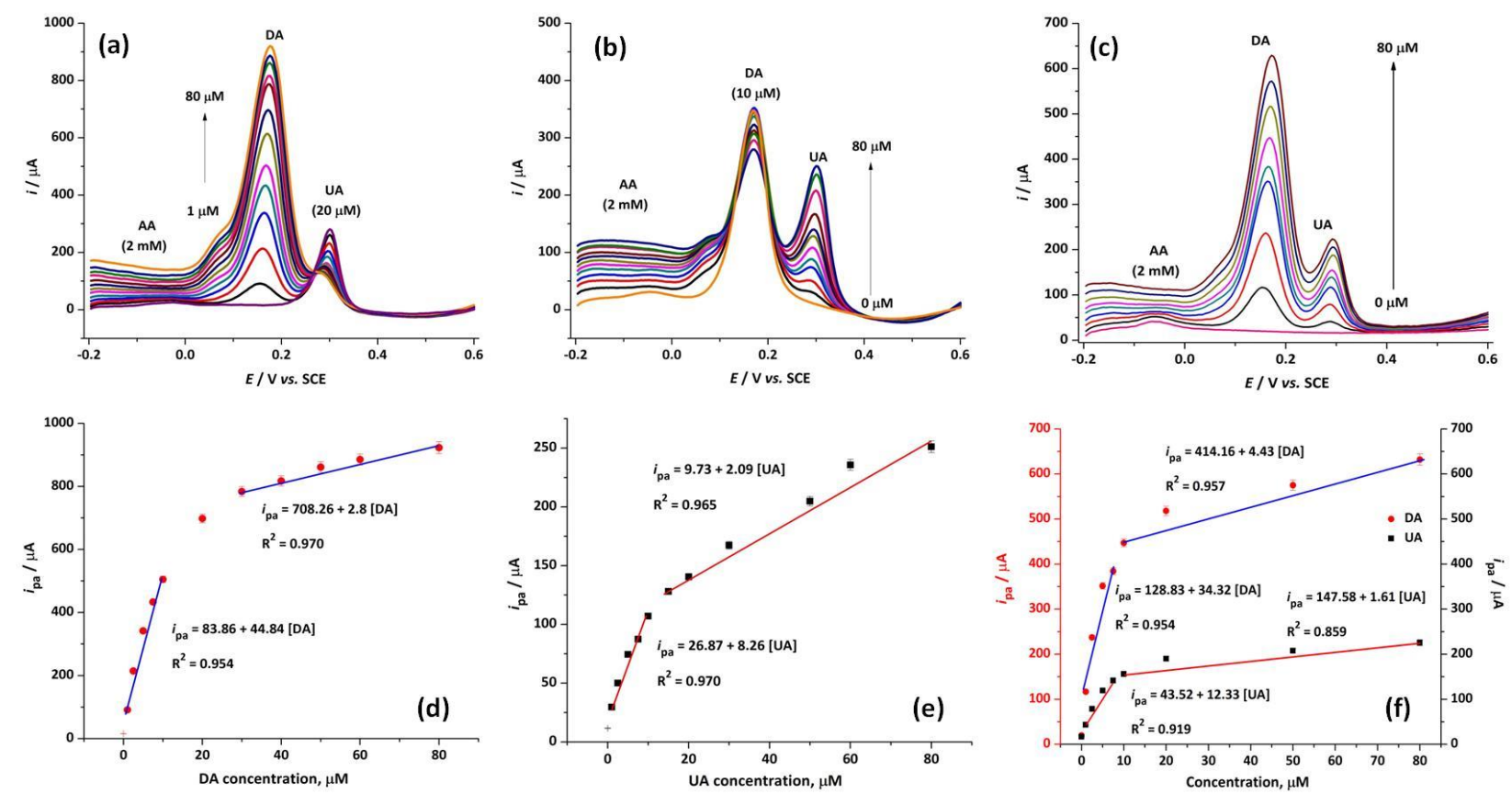

Figure 11. DPVs obtained at APGE in $0.1 \mathrm{MPBS}(\mathrm{pH}$ 7.0) with different concentrations of (a) DA containing $20 \mu \mathrm{M}$ of $U A$ and $2 \mathrm{mM}$ of $A A$, (b) UA containing $10 \mu \mathrm{M}$ of DA and $2 \mathrm{mM}$ of $A A$, and (c) DA and UA containing $2 \mathrm{mM}$ of $\mathrm{AA}$. Concentrations varied in (a-c) were 1, 2.5, 5, 7.5, 10, 15, 20, 30, 50, 60 and $80 \mu \mathrm{M}$. Corresponding calibration plots for (a), (b), and (c) are given in (d), (e) and (f).

Table 3. Comparison of the analytical performance of APGE for DA and UA determination with some previously reported modified electrodes

\begin{tabular}{|c|c|c|c|c|c|c|c|c|c|c|}
\hline \multirow{2}{*}{$\begin{array}{l}\text { Modified } \\
\text { Electrode }\end{array}$} & \multirow{2}{*}{$\begin{array}{c}\text { Pretreatment } \\
\text { Method/ Conditions }\end{array}$} & \multirow{2}{*}{$\begin{array}{c}\text { Pretreatment } \\
\text { solution }\end{array}$} & \multirow{2}{*}{$\begin{array}{l}\text { Pre-condi- } \\
\text { tioning }\end{array}$} & \multicolumn{2}{|c|}{ Linear range, $\mu \mathrm{M}$} & \multicolumn{2}{|c|}{$\mathrm{LOD}, \mu \mathrm{M}$} & \multicolumn{2}{|c|}{ Sensitivity, $\mu \mathrm{A} / \mu \mathrm{M}^{\#}$} & \multirow{2}{*}{ Ref. } \\
\hline & & & & DA & UA & DA & UA & DA & UA & \\
\hline $\begin{array}{c}\text { CTAB- } \\
\text { PANI/AC/GCE }\end{array}$ & - & $\begin{array}{l}0.1 \mathrm{M} \mathrm{PBS} \\
(\mathrm{pH} 7.0)\end{array}$ & No & $0.3-20$ & $1-20$ & 0.06 & 0.20 & 1.21 & 0.47 & [12] \\
\hline GCE & $\begin{array}{c}\mathrm{CV} / 0 \text { to } 0.9 \mathrm{~V} \\
\text { at } 30 \mathrm{mV} / \mathrm{s}\end{array}$ & $0.5 \mathrm{M} \mathrm{NaOH}$ & No & $3.0-30$ & $5.0-70$ & 2.67 & 4.7 & 0.52 & 0.19 & [56] \\
\hline GCE & $\begin{array}{c}\mathrm{CV} / 0.0 \text { to }+2.0 \mathrm{~V} \\
\text { at } 100 \mathrm{mV} / \mathrm{s}\end{array}$ & $0.1 \mathrm{M} \mathrm{H}_{2} \mathrm{SO}_{4}$ & No & $1.97-9.88$ & $19.7-98.8$ & - & - & 3.16 & 0.83 & [57] \\
\hline $\begin{array}{l}\text { poly(EBT)/ } \\
\text { GPE }\end{array}$ & $\begin{array}{c}\mathrm{CV} /-0.4 \text { to } 1.4 \mathrm{~V} \\
\text { at } 100 \mathrm{mV} / \mathrm{s}\end{array}$ & $0.05 \mathrm{M} \mathrm{H}_{2} \mathrm{SO}_{4}$ & No & $100-300$ & $200-2000$ & - & - & - & - & [58] \\
\hline PPGE & $\begin{array}{c}\mathrm{CV} / 1.5 \text { to } 2.0 \mathrm{~V} \\
\text { at } 100 \mathrm{mV} / \mathrm{s}\end{array}$ & $\begin{array}{l}0.1 \mathrm{M} \mathrm{PBS} \\
(\mathrm{pH} \mathrm{5.0)}\end{array}$ & Yes & $0.15-15$ & $0.3-150$ & 0.033 & 0.12 & 0.18 & 0.02 & [11] \\
\hline SGPGE & CA / $3 \mathrm{~V}$ for $150 \mathrm{~s}$ & $2 \mathrm{M} \mathrm{NaOH}$ & Yes & $0.15-45$ & - & 0.0082 & - & 20.81 & - & [59] \\
\hline $\begin{array}{c}\mathrm{p}(\mathrm{P} 3 \mathrm{CA}) / \\
\text { EOPGE }\end{array}$ & $\begin{array}{l}\text { CA / +1.8V V } \\
\text { for } 60 \mathrm{~s}\end{array}$ & $\begin{array}{l}0.1 \mathrm{M} \mathrm{PBS} \\
(\mathrm{pH} 7.4)\end{array}$ & Yes & $0.01-7.5$ & - & 0.0025 & - & 29.50 & - & [38] \\
\hline ETPGE & $\begin{array}{c}\mathrm{CV} /-0.3 \text { to } 2.0 \mathrm{~V} \\
\text { at } 50 \mathrm{mV} / \mathrm{s}\end{array}$ & $0.1 \mathrm{M} \mathrm{H}_{3} \mathrm{PO}_{4}$ & Yes & $0.01-5$ & - & 0.0031 & - & 17.19 & - & [39] \\
\hline APGE & $\begin{array}{l}\mathrm{CA} /+2.0 \mathrm{~V} \\
\text { for } 120 \mathrm{~s}\end{array}$ & $\begin{array}{l}0.1 \mathrm{M} \text { PBS } \\
(\mathrm{pH} 7.0)\end{array}$ & No & $1-80$ & $1-80$ & 0.008 & 0.014 & $34.32^{*}$ & $12.33^{*}$ & $\begin{array}{l}\text { This } \\
\text { Work }\end{array}$ \\
\hline
\end{tabular}

CTAB-PANI/AC/GCE - Cetyl trimethylammonium bromide - polyaniline / Activated charcoal / Glassy carbon electrode; GCE - Glassy carbon electrode; poly(EBT)/GPE - poly(Eriochrome black T) / Graphite pencil electrode; PPGE - Pretreated pencil graphite electrode; SGPGE - Surface-Graphenization Pencil Graphite Electrode; p(P3CA) / EOPGE - poly(pyrrole-3-carboxylic acid) / Electrochemically over-oxidized pencil graphite electrode; ETPGE - Electrochemically treated pencil graphite electrode; \# - Slope of the calibration plot; ${ }^{*}$ - From the slope of the calibration plot in the low concentration range.

It can be inferred from Table 3 that APGE exhibits higher sensitivity without any preconditioning of the electrode in comparison to other pretreated PGEs and GCEs. By comparing the results of other pretreated electrodes in Table 3 , it is obvious that the electrodes anodized using chronoamperometry displayed better sensitivity than electrodes modified with CV. This may be attributed to more effective oxidation of carbon surface at constant potential than during a potential sweep. LOD values were calculated using $3 \sigma / \mathrm{m}$. Here, $\sigma$ is the standard deviation of the mean value for ten DPVs of the blank solution determined according to IUPAC regulations [55] and $m$ denotes the slope estimated from the regression equation of the corresponding calibration plot. 


\section{Repeatability, reproducibility and stability}

In order to access the applicability of any electrochemical sensor, repeatability, reproducibility and stability are important figures of merit apart from sensitivity and selectivity of modified electrodes. The repeatability of APGE was determined from 10 consecutive DPV responses in $0.1 \mathrm{M}$ PBS (pH 7.0) containing $50 \mu \mathrm{M}$ DA and UA. The relative standard deviation (RSD) of $4.78 \%$ for DA and $5.29 \%$ for UA, is an indication of excellent repeatability of the modified electrode. For reproducibility study, differential pulse voltammograms of five identically prepared APGEs were obtained in $0.1 \mathrm{M}$ PBS ( $\mathrm{pH}$ 7.0) containing $50 \mu \mathrm{M}$ DA and UA. An excellent reproducibility in the electrode preparation was apparent from RSD of 6.62 and $8.37 \%$ respectively for DA and UA. The stability of APGE was determined from DPV response for $50 \mu \mathrm{M}$ DA and UA in 0.1 M PBS (pH 7.0) after one month of storage at room temperature. The long-term stability of APGE was evident from the very minor decrement in the oxidation current response for DA ( $2.85 \%)$ and UA $(3.32 \%)$.

\section{Real sample analysis}

The standard spike and recovery analysis were employed for the determination of DA in blood serum and UA in human urine samples using DPV. The recovery results are given in Table 4 and it can be seen that APGE was able to determine DA and UA with a satisfactory recovery in the range of $98-100 \%$. Thus, APGE can be utilized for real-time detection of DA and UA.

Table 4. Results for spike and recovery analysis of DA and UA in blood serum and human urine samples using APGE

\begin{tabular}{|c|c|c|c|c|}
\hline \multirow{2}{*}{ Sample } & \multirow{2}{*}{ Analyte } & \multicolumn{2}{|c|}{ Amount, $\mu \mathrm{M}$} & \multirow{2}{*}{ Recovery, \% } \\
\hline & & Added & Found & \\
\hline \multirow{3}{*}{ Blood Serum } & \multirow{3}{*}{ DA } & 30 & 29.81 & 99.36 \\
\hline & & 50 & 50.32 & 100.60 \\
\hline & & 70 & 69.24 & 98.91 \\
\hline \multirow{4}{*}{ Human Urine } & \multirow{4}{*}{ UA } & 0 & 0.15 & - \\
\hline & & 30 & 30.13 & 100.40 \\
\hline & & 50 & 50.11 & 100.20 \\
\hline & & 70 & 70.08 & 100.11 \\
\hline
\end{tabular}

\section{Conclusions}

The suitability of a disposable electrochemical sensor for DA and UA using electrochemically anodized pencil graphite electrode (APGE) was successfully demonstrated. APGE was found to simultaneously distinguish between $D A$ and $U A$ even in the presence of $2 \mathrm{mM}$ of $A A$, thereby indicating its exceptional selectivity. Moreover, the proposed APGE sensor exhibited excellent analytical performance with satisfactory results. Unlike previously reported results on pretreated pencil graphite electrodes, the proposed APGE displayed higher sensitivity with low limits of detection without any preconditioning potential. From the good recovery results observed for DA in human blood serum and UA in urine samples, the potential application of APGE in point of care analysis was established. However, there is still a scope for improving the sensor performance through further chemical modifications.

Acknowledgements: The authors thank the reviewers for their valuable comments and suggestions

\section{References}

[1] R. M. Wightman, L. J. May, A. C. Michael, Analytical Chemistry 60 (1988) 769A-779A.

[2] A. Liu, I. Honma, H. Zhou, Biosensors and Bioelectronics 21 (2005) 809-816.

[3] J. W. Mo, B. Ogorevc, Analytical Chemistry 73 (2001) 1196-1202.

[4] C. D. Salzman, M. A. Belova, J. J. Paton, Current Opinion in Neurobiology 15 (2005) 721-729. 
[5] J. M. Zen, J. J. Jou, G. Ilangovan, Analyst 123 (1998) 1345-1350.

[6] M. Alderman, K. J. V. Aiyer, Current Medical Research and Opinion 20 (2004) 369-379.

[7] E. Liberopoulos, D. Christides, M. Elisaf, Journal of Hypertension 20 (2002) 347-348.

[8] C. R. Raj, T. Ohsaka, Journal of Electroanalytical Chemistry 540 (2003) 69-77.

[9] S. H. Huang, Y. C. Shih, C. Y. Wu, C. J. Yuan, Y. S. Yang, Y. K. Li, T. K. Wu, Biosensors \& Bioelectronics 19 (2004) 1627-1633.

[10] R. J. Johnson, D. H. Kang, D. Feig, S. Kivlighn, J. Kanellis, S. Watanabe, K. R. Tuttle, B. R. Iturbe, J. H. Acosta, M. Mazzali, Hypertension 41 (2003) 1183-1190.

[11] E. Alipour, M. R. Majidi, A. Saadatirad, S. M. Golabi, A. M. Alizadeh, Electrochimica Acta 91 (2013) 3642.

[12] M. Govindasamy, S. M. Chen, V. Mani, A. Sathiyan, J. P. Merlin, F. M. A. Al-Hemaid, M. A. Ali, RSC Advances 6 (2016) 100605-100613.

[13] D. Lakshmi, M. J. Whitcombe, F. Davis, P. S. Sharma, B. B. Prasad, Electroanalysis 23 (2011) 305-320.

[14] T. Q. Xu, Q. L. Zhang, J. N. Zheng, Z. Y. Lv, J. Wei, A. J. Wang, J. J. Feng, Electrochimica Acta 115 (2014) 109-115.

[15] J. Sun, L. Li, X. Zhang, D. Liu, S. Lv, D. Zhu, T. Wu, T. You, RSC Advances 5 (2015) 11925-11932.

[16] Z. H. Sheng, X. Q. Zheng, J. Y. Xu, W. J. Bao, F. B. Wang, X. H. Xia, Biosensors and Bioelectronics 34 (2012) 125-131.

[17] J. A. Ribeiro, P. M. V. Fernandes, C. M. Pereira, F. Silva, Talanta 160 (2016) 653-679.

[18] V. S. Vasantha, S. M. Chen, Journal of Electroanalytical Chemistry 592 (2006) 77-87.

[19] Y. Wu, Z. Dou, Y. Liu, G. Lv, T. Pu, X. He, RSC Advances 3 (2013) 12726-12734.

[20] A. Safavi, N. Maleki, O. Moradlou, F. Tajabadi, Analytical Biochemistry 359 (2006) 224-229.

[21] S. Yang, G. Li, R. Yang, M. Xia, L. Qu, Journal of Solid State Electrochemistry 15 (2011) 1909-1918.

[22] B. Habibi, M. H. P. Azar, Electrochimica Acta 55 (2010) 5492-5498.

[23] M. M. Ardakani, H. Beitollahi, B. Ganjipour, H. Naeimi, M. Nejati, Bioelectrochemistry 75 (2009) 1-8.

[24] M. R. Akanda, M. Sohail, M. A. Aziz, A. N. Kawde, Electroanalysis 28 (2016) 408-424.

[25] S. Thiagarajan, S. M. Chen, Talanta 74 (2007) 212-222.

[26] M. Noroozifar, M. Khorasani Motlagh, A. Taheri, Talanta 80 (2010) 1657-1664.

[27] A. Rana, N. Baig, T. A. Saleh, Journal of Electroanalytical Chemistry 833 (2019) 313-332.

[28] A. L. Beilby, T. A. Sasaki, A. L. Beilby, Analytical Chemistry 67 (1995) 976-980.

[29] R. C. Engstrom, V. A. Strasser, Analytical Chemistry 56 (1984) 136-141.

[30] M. Mogensen, K. V. Jensen, M. J. Jorgensen, S. Primdahl, Solid State lonics 150(2002) 123-129.

[31] S. H. Huang, H. H. Liao, D. H. Chen, Biosensors and Bioelectronics 25 (2010) 2351-2355.

[32] J. Li, X. Q. Lin, Analytica Chimica Acta 596 (2007) 222-230.

[33] I. G. David, D. E. Popa, M. Buleandra, Journal of Analytical Methods in Chemistry 2017 (2017) 1-22.

[34] R. L. McCreery, Chemical Reviews 108 (2008) 2646-2687.

[35] N. Aravindan, M. V. Sangaranarayanan, Journal of Electroanalytical Chemistry 789 (2017) 148-159.

[36] S. Mondal, N. Aravindan, M. V. Sangaranarayanan, Electrochimica Acta 324 (2019) 134875-134888.

[37] H. T. Purushothama, Y. A. Nayaka, M. M. Vinay, P. Manjunatha, R. O. Yathisha, K. V. Basavarajappa, Journal of Science: Advanced Materials and Devices 3 (2018) 161-166.

[38] A. Özcan, S. İlkbaş, A. Atılır Özcan, Talanta 165 (2017) 489-495.

[39] A. Özcan, Y. Şahin, Electroanalysis 21 (2009) 2363-2370.

[40] A. J. Saleh Ahammad, S. Sarker, M. Aminur Rahman, J. J. Lee, Electroanalysis 22 (2010) 694-700.

[41] N. Vishnu, A. S. Kumar, Analytical Methods 7 (2015) 1943-1950.

[42] S. Sundaram, S. K. Annamalai, Electrochimica Acta 62 (2012) 207-217.

[43] N. Vishnu, A.S. Kumar, K.C. Pillai, Analyst 138 (2013) 6296-6300.

[44] U. J. Kim, C. A. Furtado, X. Liu, G. Chen, P. C. Eklund, Journal of the American Chemical Society 127 (2005) 15437-15445.

[45] Y. Yi, G. Weinberg, M. Prenzel, M. Greiner, S. Heumann, S. Becker, R. Schlögl, Catalysis Today 295 (2017) 32-40.

[46] A. B. Soliman, H. S. A. Samad, S. S. A. Rehim, H. H. Hassan, Scientific Reports 6 (2016) 01-12.

[47] K. Ray, R. L. McCreery, Analytical Chemistry 69 (1997) 4680-4687.

[48] T. C. Girija, M. V. Sangaranarayanan, Journal of Power Sources 156 (2006) 705-711.

[49] N. Tukimin, J. Abdullah, Y. Sulaiman, Sensors 17 (2017) 1539-1551. 
[50] Y. Zhang, J. Bin Zheng, Electrochimica Acta 52 (2007) 7210-7216.

[51] E. Laviron, Journal of Electroanalytical Chemistry 101 (1979) 19-28.

[52] N. H. Nguyen, C. Esnault, F. Gohier, D. Bélanger, C. Cougnon, Langmuir 25 (2009) 3504-3508.

[53] Z. Yu, X. Li, X. Wang, X. Ma, X. Li, K. Cao, Journal of Chemical Sciences 124 (2012) 537-544.

[54] M. M. Ardakani, M. A. Soorki, A. Khoshroo, F. Sabaghian, B. F. Mirjalili, Iranian Journal of Pharmaceutical Research 17 (2018) 851-863.

[55] Analytical Methods Committee, Analyst 112 (1987) 199-204.

[56] Z. Temoçin, Sensors and Actuators, B: Chemical 176 (2013) 796-802.

[57] S. Thiagarajan, T. H. Tsai, S. M. Chen, Biosensors and Bioelectronics 24 (2009) 2712-2715.

[58] U. Chandra, B. E. K. Swamy, O. Gilbert, S. Reddy, B. S. Sherigara, American Journal of Analytical Chemistry 2 (2011) 262-269.

[59] X. Fan, Y. Xu, T. Sheng, D. Zhao, H. Yuan, F. Liu, X. Liu, X. Zhu, L. Zhang, J. Lu, Microchimica Acta 186 (2019) 324-332.

(C)2020 by the authors; licensee IAPC, Zagreb, Croatia. This article is an open-access article distributed under the terms and conditions of the Creative Commons Attribution license (http://creativecommons. org/licenses/by/4.0/) 